\title{
REVIEW
}

\section{Heart Disease and Pregnancy}

Reza Ashrafi $\cdot$ Stephanie L. Curtis

Received: February 22, 2017 / Published online: July 5, 2017

(C) The Author(s) 2017. This article is an open access publication

\section{ABSTRACT}

Cardiac disease remains a major cause of morbidity and mortality in pregnant and post-partum women, although progress has been made, with specialist joint obstetric-cardiology clinics providing an integrated, safe and personalised service to these women. As a result, fewer non-specialist cardiologists are managing women in pregnancy with cardiovascular disease. The aim of this review is to provide a brief overview of current knowledge and practice in the field, with an emphasis on the major physiological changes which occur during pregnancy, focussing on progress through the trimesters, clinical assessment in pregnancy, management of delivery (concentrating on managed vaginal delivery), drug treatment, key conditions and risk assessment. The latter factor is particularly important in terms of being able to identify high-risk women earlier and to counsel them appropriately. Pregnant women with cardiovascular conditions can, with appropriate knowledge and counselling, be

Enhanced content To view enhanced content for this article go to http://www.medengine.com/Redeem/ 0C98F0605C0DAF54.

R. Ashrafi $(\varangle) \cdot$ S. L. Curtis

Congenital Cardiac Centre, Bristol Heart Institute, Bristol Royal Infirmary, Marlborough Street, Bristol, UK

e-mail: rezaashrafi@riseup.net managed safely in specialist multidisciplinary services, but there is a need for cardiologists to understand the key changes and risks involved in pregnancy, delivery and the post-partum period.

Keywords: Pregnancy; Heart disease; Gender

\section{INTRODUCTION}

With improved maternal medical care and fertility treatments, an increasing proportion of women with congenital cardiac disease and acquired heart disease are becoming pregnant and delivering safely [1]. However, pregnancy has a profound effect on the cardiovascular system, and many conditions are associated with a significant risk of foetal and maternal morbidity and mortality.

It has been reported that $0.2-0.4 \%$ of all pregnancies are complicated by cardiovascular disease [2], and although death is rare, cardiovascular disease is the biggest indirect cause of maternal death worldwide, with an attributable rate of two deaths per 100,000 [3] in the UK and a similar rate in other countries $[4,5]$. The epidemiology of cardiovascular disease in pregnancy varies significantly depending the location of the mother, with much variation in disease rates and processes. Worldwide, hypertensive disease in pregnancy is by 
far the most prevalent cardiovascular disorder, complicating $2-8 \%$ of all pregnancies in the Western world, predominantly in Latin America and the Caribbean, where it causes one-quarter of all maternal deaths [6]. Rheumatic heart disease is common in developing countries but are now rare in the Western world [7]. A similar variation is observed in peripartum cardiomyopathy (PPCM), with a rising incidence in Western society, estimated most recently at $1: 2229$ [8], but an estimated rate of 1:1000 in Africa and 1:300 in Haiti [6]. An exact prevalence of women with congenital cardiac disorders who are pregnant is difficult to estimate largely due to the methodology involved in the reported studies, but in the USA nine per 10,000 delivery hospitalisations were for women with congenital heart disease [9].

In most Western countries, most women seen in cardiac-obstetric services have congenital heart disease. Death is rare, but when it does occur it is most often due to myocardial infarction (often coronary dissection), ascending aortic dissection, cardiomyopathy and sudden adult cardiac death [10].

The first area addressed in this review is the physiology of the cardiovascular system during pregnancy. In this section we focus on the key changes that cardiologists need to be aware of.

This article does not contain any new studies with human or animal subjects performed by any of the authors.

\section{Physiological Changes in Pregnancy}

Pregnancy has a dramatic effect on the cardiovascular system, and the effects are sustained into the post-partum period.

Before there is even placentation, there is systemic vasodilatation at around 5 weeks gestation. Systemic vascular resistance (SVR) is progressively reduced (by 35-40\%) until the middle of the second trimester, when it plateaus before beginning to increase late in the third trimester [11]. This variation is associated with a drop in mean arterial blood pressure in the first two trimesters prior to its recovery in the third trimester to close to pre-pregnancy levels. The changes in SVR are thought to be due to the vasodilatory properties of oestrogen, progesterone and relaxin, which are all increased during pregnancy, and to reduced vasopressor receptor sensitivity. In addition, there also appears to be an increased amount of vascular nitric oxide production which contributes to the vasodilatation and reduced SVR [12].

Structurally there is a progressive increase in left ventricular end-diastolic volume and mass $[11,13]$ into the third trimester, but there is a sharp drop in left ventricular mass late in the third trimester [13]. From the first trimester onwards, there is an increase in maternal heart rate which continues throughout pregnancy [14] and is on average 30 beats per minute higher than the baseline maternal heart rate by the end of the pregnancy. These adaptations are likely to be required to cope with the extra circulating blood volume, which has increased by an average of $40 \%$, reaching a maximum value at 24 weeks.

As expected, given the physiological demands of the utero-placental circulation and the developing foetus, there is an increase in cardiac output, with the biggest increase of up to $45 \%$ from baseline occurring during the first trimester $[15,16]$. The increase in cardiac output slows late in the second trimester and drops slightly late in the third trimester [11] (but still stays above pre-pregnancy levels). Table 1 summarises the main cardiovascular physiology changes during pregnancy by trimeste, and Fig. 1 summarises the main cardiovascular physiology changes during pregnancy by trimester and percentage change.

It should be noted that these haemodynamic changes most often regress to pre-pregnancy levels, but some studies have suggested that the changes in left ventricular mass and vascular resistance do not fully return to pre-pregnancy levels.

As well as the circulatory changes described above, there are also adaptive changes that occur in the great vessels and blood that are important to women with heart disease. Expression of oestrogen receptors in the aorta causes fragmentation of reticulin fibres, reduced amount of acid mucopolysaccharides and loss of the normal arrangement of elastin fibers, 
Table 1 Summary of the key cardiovascular physiological changes which occur during pregnancy

\begin{tabular}{lllll}
\hline Variable & First trimester & Second trimester & Third trimester & Early post-partum \\
\hline SVR & $\downarrow$ & $\downarrow$ & $\downarrow$-with a late rise & $\uparrow$ \\
Heart rate & $\uparrow$ & $\uparrow$ & $\uparrow$ & $\downarrow$ \\
LVEDD & $\uparrow$ & $\uparrow$ & $\uparrow$ & $\downarrow$ \\
LV mass & $\uparrow$ & $\uparrow$ & $\uparrow$-with a late drop & $\downarrow$ \\
Cardiac output & $\uparrow$ & $\uparrow$ & $\uparrow$-with a late drop & $\downarrow$ \\
LV longitudinal strain & No change & No change & $\downarrow$ & $\uparrow$ \\
\hline
\end{tabular}

$L V$ Left ventricular, $L V E D D \mathrm{LV}$ end diastolic diameter, $S V R$ systemic vascular resistance

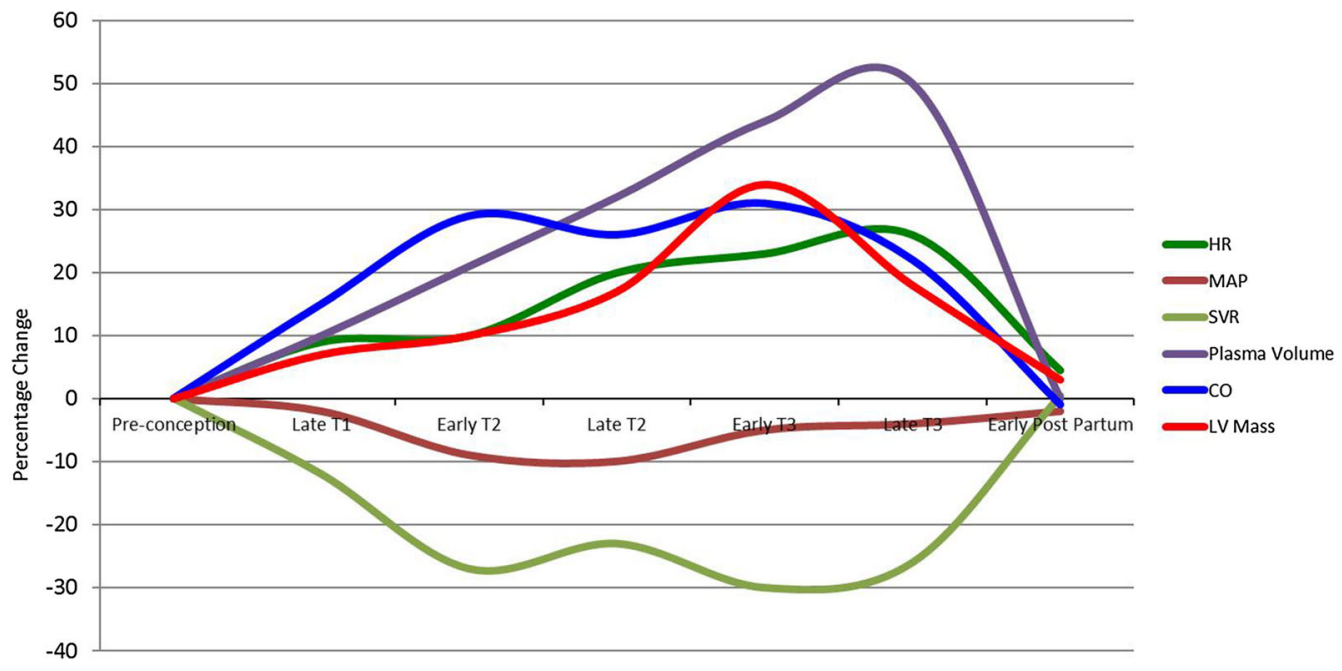

Fig. 1 Summary of the cardiovascular physiological changes in pregnancy by percentage change and trimester. $H R$ Heart rate, $M A P$ mean arterial blood pressure, $S V R$

predisposing women to aortic dissection, particularly if they have an aortopathy [17]. Additionally, pregnancy is a hypercoagulable state, designed to reduce the risk of post-partum haemorrhage [18]. This results in an increased risk of clotting, most commonly venous thromboembolism, but women who require anticoagulation for heart disease are at increased risk. For those with mechanical heart valves, pregnancy is a high-risk undertaking.

\section{PRE-CONCEPTION MANAGEMENT}

In this section we discuss those aspects of cardiac-pregnancy management which most systemic vascular resistance, $C O$ carbon dioxide, $L V$ left ventricular, $T 1, T 2, T 3$, trimester $1,2,3$, respectively

physicians feel to be of the greatest importance, and the identification of women at risk and their pre-pregnancy counselling of their own individual risk involved in pregnancy and delivery.

\section{Pre-pregnancy Counselling and Risk Assessment}

The most important aspect of assessment of reproductive-age women with cardiac disease is pre-conception counselling. Any assessment needs to cover the risks of pregnancy to the mother and foetus. Risks to the mother include whether she can tolerate the expected 
haemodynamic changes that occur in pregnancy, the need for highly medicalised antenatal care and delivery, possibly a premature delivery, that may be far from home and the long-term effects on the heart condition of a pregnancy. In the case of cardiomyopathies [19] and systemic right ventricles [20], there is evidence that pregnancy can have a deleterious long-term effect on ventricular function. In women with complex cardiovascular disorders that adversely affect their life expectancy, frank discussions need to be had about the long-term commitment of parenting and the importance of family or other social support.

Cardiopulmonary exercise testing can be useful in estimating the likelihood of complications [2]. Drugs that are contraindicated in pregnancy need to be stopped, and if cardiac function is dependent on these drugs, such as angiotensin-converting enzyme inhibitors in left ventricular dysfunction, it is important to assess the woman again when they have been drug free for several months to ensure that ventricular function does not deteriorate.

Assisted reproduction involves a wide range of techniques and medications, some of which can be invasive and lead to significant cardiac strain, with some evidence of increased complications compared to unassisted reproduction [21]. These risks should be discussed, not only with the patient before she embarks on any assisted reproduction programme but also with the cardiology team looking after the patient so as to best manage the risks. As multiple foetuses are a more common occurrence in assisted fertility programmes, the extra haemodynamic stress and likelihood of premature delivery/increased rates of hypertension also need to be discussed with the patient before she starts the programme [22].

Risks to the foetus that need to be discussed are the effects of drugs that may need to be continued and the possibility of miscarriage, prematurity, intra-uterine growth restriction and low birth weight and its implications. Detailed pre-conception counselling is especially important in the case of anticoagulation (this aspect will be discussed in more detail further in the text).

It is also important to consider the likelihood of recurrence of the disease in the case of inherited cardiac conditions and congenital heart disease. In autosomal dominant conditions, such as Marfan syndrome, many patients are aware of the inheritance risk as family members are commonly affected. However, many patients are unaware of the inheritance risk of congenital heart disease and often assume it to be higher than it is. Recurrence risk varies from 0 to $20 \%$, depending on the lesion. The most heritable lesions are left-sided obstructive conditions, such as bicuspid aortic valve disease and coarctation, and the least heritable are the transposition complexes [21-26].

There is some evidence that pre-conception multivitamins and folic acid supplementation reduces the risk of heritable congenital heart disease in the foetus $[23,24]$.

\section{Risk Assessment for Individual Cardiovascular Disorders}

Assessment of maternal risk prior to conception has been studied by several groups and refined in risk assessment scores, such as CARPREG [25] and ZAHARA [26], which are summarised in Table 2. Factors that increase the risk of maternal cardiac events include left heart obstructive lesions (aortic or mitral stenosis), cardiac symptoms, cyanosis, systemic ventricular impairment and previous cardiac events. Atrioventricular valve regurgitation (mitral or tricuspid) also confers an increased risk. However, the most high-risk situation is the presence of a mechanical valve and the associated risk of full anticoagulation.

The current European Society of Cardiology guidelines suggest using the modified World Health Organisation (WHO) system [27] when assessing women prior to pregnancy, and this forms the basis for the small number of conditions that are thought to be a contraindication to pregnancy (shown in Table 3). 
Table 2 CARPREG and ZAHARA scoring systems for estimating the risk of a cardiac complication during pregnancy

\begin{tabular}{|c|c|c|c|}
\hline \multicolumn{2}{|c|}{ Risk factor in CARPREG scoring ( 1 point for each factor) } & Total points & Risk of a cardiac complication (\%) \\
\hline \multicolumn{2}{|c|}{ Prior event (e.g. arrhythmia, stroke, heart failure) } & 0 & 5 \\
\hline \multicolumn{2}{|l|}{ NYHA class $>$ II or cyanosis } & 1 & 27 \\
\hline \multicolumn{2}{|l|}{ Left heart obstruction } & $>1$ & 75 \\
\hline \multicolumn{4}{|l|}{ Systemic ventricular dysfunction } \\
\hline \multicolumn{2}{|l|}{ Risk factor in ZAHARA } & Total points & Risk of a cardiac complication (\%) \\
\hline Prior arrhythmias & 1.5 & 0 & 2.9 \\
\hline NYHA $>2$ & 0.75 & $0.5-1.5$ & 7.5 \\
\hline Left heart obstruction & 2.5 & $1.51-2.50$ & 17.5 \\
\hline Cardiac medications at baseline & 1.5 & $2.51-3.50$ & 43.1 \\
\hline Systemic AV valve regurgitation & 0.75 & $>3.51$ & 70.0 \\
\hline Sub pulmonary AV valve regurgitation & 0.75 & & \\
\hline Mechanical valve prosthesis & 4.5 & & \\
\hline Cyanotic heart disease & 1.0 & & \\
\hline
\end{tabular}

CARPREG CARdiac Disease in PREGnancy, ZAHARA Zwangerschap bij Aangeboren HARt Afwijkingen I, $A V$ atrioventricular, NYHA New York Heart Association

\section{PREGNANCY AND PRE-DELIVERY}

After the key phase of pre-assessment, and care focusses on the assessment during pregnancy and the management of specific conditions.

\section{Clinical Assessment and Investigations During Pregnancy}

Cardiac assessment of the pregnant patient can be difficult as common symptoms of pregnancy, such as breathlessness and fatigue, can mimic cardiac symptoms. Also, clinical signs, such as mild dependent oedema, a minimally raised jugular venous pressure, collapsing pulses and an ejection systolic murmur, are common in pregnancy and can result in difficult assessments [28]. Signs and symptoms which are abnormal in pregnancy include extreme breathlessness, marked oedema, a fourth heart sound, diastolic murmurs, jugular venous pressure of $>2 \mathrm{~cm}$ and a persistent tachycardia of $>100$ beats per minute; any one of these should prompt further evaluation [29].
Electrocardiography (ECG) is a common and useful diagnostic tool throughout pregnancy for complaints such as chest pain/arrhythmias. Subtle changes in the ECG are common in later pregnancy and include left axis deviation, inverted $\mathrm{T}$ waves and inferior $\mathrm{Q}$ waves due to diaphragmatic elevation [30]. Chest radiography is a safe investigation modality in pregnancy and should be performed readily as required [31].

After the ECG, the most common investigation that most cardiologists will utilise is the echocardiogram, which is based on ultrasound and therefore safe throughout the pregnancy. As would be predicted from the changes in maternal physiology, there is an observable increase in left ventricular diameter measurements on echocardiography, such as the left ventricular end diastolic and systolic dimensions [32]. Assessment of ventricular function is made utilising identical techniques to those used in the non-pregnant women, with ejection fraction, tissue Doppler and m-mode measurements all useful in serial monitoring. There have been some inconsistencies in the reporting 
Table 3 Modified World Health Organisation system for risk assessment of cardiac conditions in pregnancy

\section{World Health Organisation system Description \\ for risk assessment}

WHO 1

WHO 2

WHO 2-3

WHO 3
Risk no higher than general population

-Uncomplicated, small or mild pulmonary stenosis, mitral valve prolapse, patent duct

-Successfully repaired simple lesions such atrial septal defect, ventricular septal defect, anomalous veins, patent duct

-Isolated atrial or ventricular ectopics

Small increased risk of maternal mortality and morbidity

-Unrepaired simple atrial septal defect/ventricular septal defect

-Repaired Tetralogy of Fallot

-Most arrhythmogenic disorders

-Left ventricular dysfunction with ejection fraction $>30 \%$ and NYHA Class $<$ III

-Hypertrophic cardiomyopathy

-Non-severe native heart valve disease

-Tissue replacement valve

-Repaired coarctation

-Marfan syndrome without aortic dilatation

-Aorta less than $45 \mathrm{~mm}$ in bicuspid aortic valve disease

Significant increased risk of maternal mortality and morbidity. Expert cardiac and obstetric pre-pregnancy, antenatal and postnatal care required

-Mechanical valve

-Systemic right ventricle

-Fontan circulation

-Unrepaired cyanotic heart disease

-Other complex congenital heart disease

-Aortic dilatation 40-45 mm in Marfan syndrome

-Aortic dilatation $45-50 \mathrm{~mm}$ in bicuspid aortic valve disease 
Table 3 continued

\begin{tabular}{|c|c|}
\hline $\begin{array}{l}\text { World Health Organisation system } \\
\text { for risk assessment }\end{array}$ & Description \\
\hline WHO 4 & $\begin{array}{l}\text { Pregnancy contraindicated: very high risk of maternal mortality or severe } \\
\text { morbidity. Termination should be discussed. If pregnancy continues, care as for } \\
\text { Class } 3 \\
\text {-Pulmonary arterial hypertension } \\
\text {-Severe systemic ventricular dysfunction-ejection fraction }<30 \% \text { and NYHA } \\
\text { II-IV } \\
\text {-Severe aortic or mitral stenosis } \\
\text {-Previous peripartum cardiomyopathy with residual LV impairment } \\
\text {-Marfan syndrome with aorta dilated }>45 \mathrm{~mm} \\
\text {-Aortic dilatation }>50 \mathrm{~mm} \text { in bicuspid aortic valve disease } \\
\text {-Native severe coarctation }\end{array}$ \\
\hline
\end{tabular}

WHO World Health Organisation

of alterations in measurements during the pregnancy period, with some studies reporting no change and others reporting a small drop late in pregnancy $[32,33]$. When assessing left ventricular function there does seem to be agreement across several studies that later in pregnancy the left ventricle becomes more globular in shape, accompanied by a drop in left ventricular longitudinal function and strain $[32,34,35]$; this would be in keeping with the late rise in afterload caused by the slight increase in SVR [34].

In the assessment of valvular lesions using echocardiography, pregnancy-related changes can often affect the severity of a valve lesion or the measurement made by echocardiography. In the context of stenotic valvular lesions, the extra volume load and heart rate increase seen in pregnancy can lead to an increase in the gradient measured across a valve without any observable change in the valve area measured by, for example, the continuity equation [36]. When measuring valve regurgitation, it is important to note that the extra volume load in pregnancy leads to an increase in observable tricuspid regurgitation without necessarily any change in the valve function; in contrast, mitral regurgitation, despite the extra volume load, often appears less during pregnancy due to the drop in SVR [37]. It is important for cardiologists to undertake serial scans and look at trends in valve pathology, and these changes need to be accompanied by clinical assessment.

Cross-sectional imaging can be extremely valuable in diagnosis and surveillance during pregnancy. Cardiac magnetic resonance imaging is safe after the first trimester although gadolinium injection is not used due to a lack of data on its safety [38]. Computed tomography involves ionising radiation but may be required in spite of this drawback in life-threatening scenarios, such as a concern about aortic dissection or pulmonary embolus. Cardiac catheterisation should be avoided in pregnancy but if required (for example in emergency pacing) the radiation dose should be minimised as much as possible and lead shielding used across the abdomen to reduce foetal exposure [39].

\section{Common and Important Cardiovascular Disorders Encountered During Pregnancy}

Specific guidance on some of the more commonly encountered conditions and important high-risk conditions are discussed in this section. 


\section{Systemic Ventricular Dysfunction}

The incidence of systemic ventricular dysfunction solely in pregnancy is difficult to separate from dysfunction related to other conditions, but in the European Society of Cardiology's ROPAC registry (Registry Of Pregnancy And Cardiac disease) cardiomyopathies represent 7\% of the total registry [40]. The normal physiological changes of pregnancy of increased heart rate, cardiac output and circulating volume are particularly problematic for women with impaired systemic ventricular function. These women often experience a worsening of symptoms, particularly from around 16 weeks of gestation. Some women who are not diagnosed prior to pregnancy may be erroneously diagnosed with asthma or respiratory tract infections before the diagnosis of cardiomyopathy is made. Ventricular dysfunction due to ischaemic heart disease is very uncommon; most women have familial or idiopathic dilated cardiomyopathy. Some may have had previous chemotherapy or previous peripartum cardiomyopathy. Diagnosis is made clinically and most commonly in conjunction with echocardiography, with dysfunction often seen as a worsening on serial echocardiography. More recently, medical units have begun to incorporate serial B-type natriuretic peptide (BNP) as a method for monitoring women with ventricular dysfunction; a worsening in their condition can be then identified earlier, and BNP is also a good negative predictive marker if $<100$ [41].

Heart failure symptoms in pregnancy should be managed with rest and, as angiotensin-converting enzyme inhibitors and angiotensin receptor blockers are contraindicated, a combination of hydralazine and nitrate can be used to reduce cardiac afterload. Some women may need diuretics, although due to the pregnancy-related increase in glomerular filtration rate, fewer diuretics than normal may be needed. Beta-blockers can also be a useful adjunct therapy, and cardo-selective beta-blockers, such as bisoprolol and metoprolol, are more preferred. Regular foetal growth scans are needed. Careful assessment of the likelihood of the pregnancy reaching viability needs to be assessed, and occasionally the decision may be made that continuing the pregnancy represents too high a risk to the mother, with advice that the pregnancy be terminated on medical grounds.

Women may require in-patient treatment and rest, and early delivery may be needed. The maternal mortality recorded in the ROPAC for cardiomyopathies is $2.4 \%$, but the need for hospital admission is 33\% [40]. Prognosis in pregnancy for ventricular dysfunction as illustrated earlier based on data in the WHO scoring system and others is dependent on the level of ventricular dysfunction and symptom severity $[27,42]$.

Peripartum cardiomyopathy is diagnosed when acute left ventricular impairment occurs between the last 4 weeks of pregnancy and 5 months post-partum [43]. The aetiology is unknown, and there is a wide geographical variation in frequency, with countries such as Haiti having a particularly high prevalence. Recent experimental work suggests a potential pathogenic role for prolactin [44] and an overlap with hypertensive disorders and pre-eclampsia [45]. Treatment should be as for other types of heart failure. Bromocriptine, a prolactin-blocking drug, has been used on a case-by-case basis [46] and in a small trial [47], with some positive results and is currently undergoing testing in a larger randomised control trial. The drug has the disadvantage of precluding breast-feeding [47], and there maybe some evidence that breast-feeding improves recovery in PPCM [48]. Prompt echocardiography is essential for early diagnosis, and a low index of suspicion for the condition is needed. Response to treatment varies widely, with some women recovering fully and some requiring heart transplantation or even dying. Positive predictive factors are early diagnosis, having an ejection fraction of $>30 \%$ or a left ventricular end diastolic dimension of $<6.0 \mathrm{~cm}$ at the time of diagnosis [49]. Approximately $50 \%$ of women recover fully at 6 months and the condition can recur in $25 \%$ women, with those with residual left ventricular function faring worse in subsequent pregnancies [50]. Left ventricular recovery and survival differs between ethnic groups, with African-American women doing worse than Caucasians despite comparable treatment [51]. 


\section{Left Heart Obstruction}

In the ROPAC registry, aortic stenosis and mitral stenosis are the two most common left-sided obstructive lesions, accounting for $31 \%$ of the valvular heart disease patients seen in the registry [52]. To date there are insufficient data available worldwide on the incidence of other obstructive lesions, such subvalvular or supravalvular lesions or hypertrophic cardiomyopathy with an obstructive gradient. Due to the extra volume load and inability to increase cardiac output across a fixed obstruction associated with both aortic and mitral stenosis, these conditions are significantly problematic during pregnancy and carry a high risk of morbidity and mortality [53, 54]. Symptoms and signs often include increasing breathlessness, fatigue and oedema, and diagnosis if unknown prior to conception is usually confirmed with echocardiography.

For mitral stenosis, the mainstay of treatment is rest, beta-blockade and diuretics for heart failure symptoms. Percutaneous balloon valvuloplasty has been widely used in rheumatic mitral stenosis and should be performed readily if the woman develops symptoms or foetal growth is compromised [55]. Aortic stenosis is better tolerated but often more problematic as the options for treatment are limited. It is often due to bicuspid valve disease, and the results from balloon valvuloplasty are not so predictable or successful. Diuresis is not helpful, nor is beta-blockade. In both conditions, there is an increased risk of prematurity and intra-uterine growth restriction [56]. In moderate mitral stenosis and severe aortic stenosis, decisions around delivery often need to be made on a week by week basis as pregnancy progresses.

\section{Arrhythmias}

Many women experience palpitations during pregnancy that are not of clinical concern, but a small number of women with pre-existing or new diagnosed rhythm disorders may need treatment during pregnancy. Initial management should be as for any other patient with rhythm disorder: prompt diagnosis based on ECG and appropriate medical treatment [57]. Safe therapies for tachyarrhythmias during pregnancy include adenosine, digoxin, flecainide and verapamil. Beta-blockers can cause intra-uterine growth restriction, but they are an effective therapy against most tachyarrhythmias in pregnancy. In the context of clinical compromise and haemodynamic instability, electrical cardioversion should be used as normal, and no detrimental effects have been reported on the foetus due to electrical cardioversion, although foetal assessment afterwards is recommended [58].

Atrial fibrillation should be managed as in the non-pregnant patient, with attention paid to the need, or not, for anti-coagulation prior to or following a cardioversion.

Catheter ablation is reserved for drug-resistant arrhythmias leading to haemodynamic compromise or refractory symptoms and if needed can be performed without fluroscopy [59].

Ventricular arrhythmias (VAs) are much less common in pregnancy than supraventricular arrhythmias and occur most commonly in women with known heart disease at a frequency of approximately 1\% [25]. VAs in women with heart disease occur most commonly late in pregnancy, usually in the third trimester with symptoms of heart failure [60]. Management, as stated earlier, should be as for the non-pregnant woman, with medications (amiodarone avoided) and defibrillator [implanted cardioverter defibrillator (ICD)] therapy as needed or emergency cardioversion. Pregnancy itself does not seem to lead to an excess of ICD therapies [61].

Congenital long QT syndromes are associated with a risk of syncope and ventricular arrhythmias and a small risk of sudden death. Pregnancy is associated with a reduced risk of events during pregnancy but an increased risk of events in the first 9 months post-partum [62], with the risk being most marked for long QT2 [62]. It is safe to go through pregnancy with an ICD and important not to switch the device off during delivery. If Caesarean section is required unipolar diathermy should be avoided.

Bradyarrhythmias are much less common in pregnancy, and permanent pacing is rarely required [63]; however, if required, radiation exposure should be minimised. Some units have 
suggested isoproterenol can be used safely if needed in an emergency situation [64].

\section{Coronary Artery Disease}

Coronary artery dissection, normally a rare occurrence, is significantly more common in pregnancy, with $>20 \%$ of all cases of spontaneous dissection involving pregnant women [65]. However, atherosclerotic coronary artery disease, which is the major burden of acquired cardiovascular disease worldwide, is becoming an increasing problem in pregnancy as women with traditional cardiovascular risk factors are becoming pregnant at an older age [66].

The rate of maternal mortality due to an acute coronary syndrome is thought to be $5-10 \%$ and, as with aortic dissection, peaks in the peripartum period. Pregnant women presenting with chest pain should be assessed in the usual way with an ECG and appropriate biomarkers, such as troponin. Traditional risk factors do determine the risk in the pregnant woman in the same way as in the normal population, and these should be used in the risk assessment.

Treatment of an acute myocardial infarction should proceed as normal, with emergency angioplasty used per guidelines with bare metal stents as these have the widest historical evidence base in the pregnant woman [2]. Thrombolysis should not be performed as coronary artery dissection is so often the cause. Clopidogrel as a dual anti-platelet may be added to the therapeutic regimen for use in as short a course as possible following stenting; there is currently no evidence available for prasugrel or ticagrelor. If clopidogrel is prescribed, then the administration of an epidural is not safe. Although the above caveats need to be borne in mind, the most important part of management is to treat the mother in the most effective way possible to save her life.

\section{Congenital Heart Disease}

In developed countries, most women seen in cardiac-obstetric clinics have congenital heart disease [67]. Due to advances in cardiac surgery and paediatric intensive care almost all children born with congenital heart disease now survive to adulthood, with increasingly complex conditions. Many of these children want themselves to have children. Given the wide spectrum of lesions and repairs, women with congenital heart disease should be managed jointly between obstetricians and specialist cardiologists. This spectrum of disorders in pregnancy is reviewed in detail elsewhere [68].

\section{Aortopathies}

Aortopathies, such as Marfan syndrome, present a significant risk in pregnancy, with increased blood volume and vascular histological changes leading to increased risks of dissection. Dissection most commonly occurs in the third trimester and in the post-partum period, and those patients with dilated aortas and a family history of dissection are at greatest risk. Type B dissection is unpredictable. Frequent surveillance by ECG during pregnancy is important, and the dissection risk can be reduced by beta-blockade [69]. Delivery should be highly medicalised with a combined spinal-epidural and passive second stage. Very high-risk cases may need Caesarean section in cardiac theatres. Women should remain in hospital for 1 week after delivery.

Women with dilated aortas in the context of a bicuspid aortic valve are at much less risk of dissection [70], although regular surveillance by ECG during pregnancy is still important, and beta-blockade and a medicalised delivery may be recommended if the aorta is particularly dilated.

Turner's syndrome deserves a special mention as some mosaic patients do become pregnant. Around one-half of women with Turner's syndrome will have a cardiac defect (the most common being a bicuspid aortic valve and coarctation of the aorta). A large number are hypertensive. Moreover, Turner's syndrome is an independent risk factor for aortic dissection, and these patients should be managed as those with Marfan syndrome. It is important to take account of body surface area when measuring aortic size; these women are of small stature and the absolute aortic measurements may be normal. 
Table 4 Common cardiac drugs and their risks in pregnancy

\begin{tabular}{|c|c|c|c|}
\hline Drug & $\begin{array}{l}\text { Crosses } \\
\text { placenta } \\
\text { (yest/no) }\end{array}$ & $\begin{array}{l}\text { In breast } \\
\text { milk (yes/ } \\
\text { no) }\end{array}$ & Foetal adverse effects \\
\hline $\begin{array}{l}\text { Angiotensin-converting enzyme } \\
\text { inhibitors/angiotensin receptor } \\
\text { blockers }\end{array}$ & Commonly & Commonly & $\begin{array}{l}\text { Renal or tubular dysplasia, oligohydramnios, growth } \\
\text { retardation, ossification disorders of skull, lung } \\
\text { hypoplasia, contractures, anaemia, intrauterine death }\end{array}$ \\
\hline Adenosine & No & No & No reported effects \\
\hline Amiodarone & Yes & Yes & $\begin{array}{l}\text { Foetal hypothyroidism, bradycardia and growth } \\
\text { retardation }\end{array}$ \\
\hline Aspirin & Yes & Yes & No reported effects \\
\hline Beta-blockers & Yes & Yes & Bradycardia, low birthweight, hypoglycaemia \\
\hline Clopidogrel & Unknown & Unknown & No information available \\
\hline Digoxin & Yes & Yes & No reported effects \\
\hline Dilitiazem & No & Yes & Possibly teratogenic \\
\hline Flecainide & Yes & Yes & Bradycardia—safe for foetal tachycardia \\
\hline Furosemide & Yes & Yes & Oligohydraminos \\
\hline Clexane & No & No & No reported effects \\
\hline Heparin & No & No & No reported effects \\
\hline Hydralazine & No & No & Foetal tachyarrhythmias \\
\hline Methyldopa & Yes & Yes & Mild neonatal hypotension \\
\hline Nifedipine & Yes & Yes & No reported effects. Tocolytic \\
\hline Spironolactone & Yes & Yes & Anti-androgenic and cleft abnormalities \\
\hline Statins & Yes & Unknown & Congenital anomalies \\
\hline Verapamil & Yes & Yes & No reported effects \\
\hline Warfarin & Yes & Yes-inactive & Embryopathy, foetal loss, haemorrhage \\
\hline
\end{tabular}

\section{Management of Pharmacological Treatment in Pregnancy and Post-partum}

Women with existing cardiac disorders were possibly on a variety of medications prior to trying to become pregnant, and the decision to continue these medications during pregnancy is based on balancing the risk to the mother of stopping them, the availability of a safe alternative and the risk to the foetus. Due to the ethical issue of performing clinical trials in pregnant women the only data on drugs in pregnancy are from observational studies and based on evidence from animal trials. Whenever possible, prior to conception drugs considered to be unsafe during pregnancy should be stopped. However, many drugs need to be continued in pregnancy, and close liaison with foetal medicine specialists is important.

A summary of the risk of common cardiac drugs during pregnancy are listed below in Table 4 [2].

Anti-coagulation is a source of problems in pregnancy. Warfarin is associated with foetal 
embryopathy, haemorrhage and a foetal loss rate of up to $35 \%$ [39]. Where possible it should be substituted for low-molecular-weight heparin (LMWH), which does not cross the placenta. However in the case of mechanical valves warfarin results in significantly less valve thrombosis than unfractionated heparin or LMWH [71, 72]. Some women choose to substitute warfarin with LMWH for the period of embryopathy risk (6-12 weeks of gestation) and then resume taking warfarin for most of the pregnancy. Because warfarin crosses the placenta, vaginal delivery is unsafe for the foetus, and so warfarin is stopped and substituted with LMWH at 36 weeks. If labour begins prematurely when the woman is still taking warfarin, a caesarean section must be performed. Some studies have suggested that doses of $>5 \mathrm{mg}$ are associated with more complications that lower doses [73-75], but this finding is not universal [76].

Currently there is no universally agreed upon strategy for the monitoring of enoxaparin use, with some centres using solely peak or trough levels of factor $\mathrm{Xa}$, or both [77], and the strategy decided upon may be particularly important in the first trimester due to larger proportional changes in plasma volume and creatinine clearance [78].

\section{Management of Labour and Delivery in Women with Cardiovascular Disorders}

The follow-up and delivery of high-risk pregnancy patients fitting into WHO class 3 [7, 42] should occur in experienced centres where combined experienced anaesthetic, obstetric, cardiology and foetal care can be provided. During follow-up visits and assessments in specialist cardiac-obstetric clinic, an individualised birth plan is drawn up jointly between the cardiac and obstetric teams, and this formal plan is placed in each woman's medical notes so that accepting teams at non-specialist centres have the appropriate information for a safe delivery in an emergency. In many cases labour can be awaited naturally, although in some cases in which there is a desire to deliver early due to maternal complications, or for geographical reasons to allow for delivery in a specialist centre, induction of labour may be recommended .

Women with cardiovascular disorders have for many years been subject to a higher rate of Caesarean sections compared to other women, and it has been suspected that this is due to a clinician's perception of the risk involved in changing to an emergency Caesarean section [79]. Caesarean section is associated with more profound and sudden haemodynamic changes, greater blood loss, increased risk of infection and dramatically increased risk of venous thromboembolism [80]. Furthermore, a Caesarean section will significantly affect the mode of future deliveries. The combination of a carefully titrated combined spinal-epidural, passive second-stage and assisted delivery with forceps allow a "pain free, pushing free labour" that is more physiological and safer for the mother $[28,81]$. However, it must be done in experienced hands by a specialist team. Caesarean section is reserved for obstetric indications; in rare cases, if there is a very high risk of aortic dissection, a planned delivery in theatres with a cardiac surgeon on stand-by is recommended.

The third stage of labour is usually facilitated by the administration of syntometrine, which causes uterine contractions and minimises post-partum haemorrhage. However, this drug also has a pronounced hypertensive and vasoconstrictive effect and so is avoided in most women with heart disease in favour of a slow infusion of syntocinon (an oxytocin analogue) [82]. Misoprostol may be used for post-partum haemorrhage, with syntometrine reserved only for severe maternal haemorrhage where the benefit outweighs the risk [82].

\section{POST-PARTUM EVALUATION AND MANAGEMENT OF WOMEN WITH CARDIOVASCULAR DISORDERS}

Whilst pre-pregnancy assessment and surveillance during pregnancy are very important, post-partum follow-up is also important to assess for deterioration following pregnancy 
[20] and to monitor for peripartum cardiomyopathy, which can occur late in the post-partum period. Some conditions, such as long QT and Marfan syndrome, seem to be associated with more complications in the post-partum period, and advising women accordingly is important prior to discharge. Post-partum follow-up also allows for the reintroduction of important cardiac medications whose use may have been altered during pregnancy, such as angiotensin-converting enzyme inhibitors or warfarin.

Post-partum is a key opportunity to discuss contraception and the options available to women to reduce the risk of an unplanned pregnancy, as well as to allow recovery from the most recent pregnancy, especially in the context of peripartum cardiomyopathy.

\section{CONCLUSION}

Pregnancy presents the heart with a unique physiological challenge. An increasing number of women with cardiac disease are going through pregnancy successfully. The range of conditions encountered is wide, and many patients have congenital heart disease. There are multiple management challenges to achieve a successful outcome for mother and child. Pre-pregnancy counselling is vital, and specialist multi-disciplinary care by a specialist team is essential to ensure a successful outcome for mother and child.

\section{ACKNOWLEDGEMENTS}

No funding or sponsorship was received for this study or publication of this article. All named authors meet the International Committee of Medical Journal Editors (ICMJE) criteria for authorship for this manuscript, take responsibility for the integrity of the work and have given final approval for the version to be published.

Disclosures. Reza Ashrafi and Stephanie L Curtis have nothing to disclose.
Compliance with Ethics Guidelines. This article does not contain any new studies with human or animal subjects performed by any of the authors.

Open Access. This article is distributed under the terms of the Creative Commons Attribution-NonCommercial 4.0 International License (http://creativecommons.org/licenses/ by-nc/4.0/), which permits any noncommercial use, distribution, and reproduction in any medium, provided you give appropriate credit to the original author(s) and the source, provide a link to the Creative Commons license, and indicate if changes were made.

\section{REFERENCES}

1. Thompson JL, Kuklina EV, Bateman BT, Callaghan WM, James AH, Grotegut CA. Medical and obstetric outcomes among pregnant women with congenital heart disease. Obstet Gynecol. 2015;126:346-54.

2. Regitz-Zagrosek V, Blomstrom Lundqvist C, Borghi C, Cifkova R, Ferreira R, Foidart J-M, Gibbs JSR, Gohlke-Baerwolf C, Gorenek B, Iung B, Kirby M, Maas AHEM, Morais J, Nihoyannopoulos P, Pieper PG, Presbitero P, Roos-Hesselink JW, Schaufelberger M, Seeland U, Torracca L, Bax J, Auricchio A, Baumgartner $\mathrm{H}$, Ceconi C, Dean V, Deaton C, Fagard R, Funck-Brentano C, Hasdai D, Hoes A, Knuuti J, Kolh P, McDonagh T, Moulin C, Poldermans D, Popescu BA, Reiner Z, Sechtem U, Sirnes PA, Torbicki A, Vahanian A, Windecker S, Baumgartner H, Deaton C, Aguiar C, Al-Attar N, Garcia AA, Antoniou A, Coman I, Elkayam U, Gomez-Sanchez MA, Gotcheva N, Hilfiker-Kleiner D, Kiss RG, Kitsiou A, Konings KTS, Lip GYH, Manolis A, Mebaaza A, Mintale I, Morice M-C, Mulder BJ, Pasquet A, Price S, Priori SG, Salvador MJ, Shotan A, Silversides CK, Skouby SO, Stein J-I, Tornos P, Vejlstrup N, Walker F, Warnes C. ESC Guidelines on the management of cardiovascular diseases during pregnancy. The task force on the management of cardiovascular diseases during pregnancy of the european society of cardiology (ESC). Eur Heart J. 2011;32:3147-97.

3. Knight M, Nair M, Tuffnell D, Kenyon S, Brocklehurst P, Shakespeare J, Gray R, Kurinczuk JJ (eds) On behalf of MBRRACE-UK. Saving lives, improving mothers' care-surveillance of maternal deaths in the UK 2012-2014 and lessons learned to inform maternity care from the UK and Ireland confidential enquiries into maternal deaths and morbidity 
2009-2014. 2016. Oxford: National Perinatal Epidemiology Unit, University of Oxford.

4. Kuriya A, Piedimonte S, Spence AR, Czuzoj-Shulman N, Kezouh A, Abenhaim HA. Incidence and causes of maternal mortality in the USA. J Obstet Gynaecol Res. 2016;42:661-8.

5. Bamber JH, Kinsella SM. MBRRACE-UK-the new home for the confidential enquiries into maternal deaths-reports for the first time. Anaesthesia. 2015;70:5-9.

6. Sliwa K, Böhm M. Incidence and prevalence of pregnancy-related heart disease. Cardiovasc Res. 2014;101:554-60.

7. Seckeler MD, Hoke TR. The worldwide epidemiology of acute rheumatic fever and rheumatic heart disease. Clin Epidemiol. 2011;3:67-84.

8. Hilfiker-Kleiner D, Haghikia A, Nonhoff J, Bauersachs J. Peripartum cardiomyopathy: current management and future perspectives. Eur Heart J. 2015;36:1090-7.

9. Thompson JL, Kuklina EV, Bateman BT, Callaghan WM, James AH, Grotegut CA. Medical and obstetric outcomes among pregnant women with congenital heart disease. Obstet Gynecol. 2015;126:346-54.

10. Cantwell R, Clutton-Brock T, Cooper G, Dawson A, Drife J, Garrod D, Harper A, Hulbert D, Lucas S, McClure J, Millward-Sadler H, Neilson J, Nelson-Piercy C, Norman J, O'Herlihy C, Oates M, Shakespeare J, de Swiet M, Williamson C, Beale V, Knight M, Lennox C, Miller A, Parmar D, Rogers J, Springett A. Saving mothers' lives. Reviewing maternal deaths to make motherhood safer: 2006-2008. The Eighth Report of the Confidential Enquiries into Maternal Deaths in the United Kingdom. BJOG. 2011;118[Suppl 1]:1-203.

11. Meah VL, Cockcroft JR, Backx K, Shave R, Stohr EJ. Cardiac output and related haemodynamics during pregnancy: a series of meta-analyses. Heart. 2016;102:518-26.

12. Sladek SM, Magness RR, Conrad KP. Nitric oxide and pregnancy. Am J Physiol. 1997;272:R441-63.

13. Ducas RA, Elliott JE, Melnyk SF, Premecz S, daSilva M, Cleverley K, Wtorek P, Mackenzie GS, Helewa ME, Jassal DS. Cardiovascular magnetic resonance in pregnancy: insights from the cardiac hemodynamic imaging and remodeling in pregnancy (CHIRP) study. J Cardiovasc Magn Reson. 2014;16:1.

14. Mahendru AA, Everett TR, Wilkinson IB, Lees CC, McEniery CM. A longitudinal study of maternal cardiovascular function from preconception to the postpartum period. J Hypertens. 2014;32:849-56.

15. Robson SC, Hunter S, Boys RJ, Dunlop W. Serial study of factors influencing changes in cardiac output during human pregnancy. Am J Physiol. 1989;256:H1060-5.

16. Hunter S, Robson SC. Adaptation of the maternal heart in pregnancy. Br Heart J. 1992;68:540-3.

17. Nolte JE, Rutherford RB, Nawaz S, Rosenberger A, Speers WC, Krupski WC. Arterial dissections associated with pregnancy. J Vasc Surg. 1995;21:515-20.

18. Kupferminc MJ. Thrombophilia and pregnancy. Reprod Biol Endocrinol. 2003;1:111.

19. Stergiopoulos K, Shiang E, Bench T. Pregnancy in patients with pre-existing cardiomyopathies. J Am Coll Cardiol. 2011;58:337-50.

20. Bowater SE, Selman TJ, Hudsmith LE, Clift PF, Thompson PJ, Thorne SA. Long-term outcome following pregnancy in women with a systemic right ventricle: is the deterioration due to pregnancy or a consequence of time? Congenit Heart Dis. 2013;8:302-7.

21. Thomopoulos C, Tsioufis C, Michalopoulou H, Makris T, Papademetriou V, Stefanadis C. Assisted reproductive technology and pregnancy-related hypertensive complications: a systematic review. J Hum Hypertens. 2013;27:148-57.

22. Qin J, Wang H, Sheng X, Liang D, Tan H, Xia J. Pregnancy-related complications and adverse pregnancy outcomes in multiple pregnancies resulting from assisted reproductive technology: a meta-analysis of cohort studies. Fertil Steril. 2015;103:1492-508.e1-7

23. Feng $\mathrm{Y}$, Wang $\mathrm{S}$, Chen $\mathrm{R}$, Tong $\mathrm{X}, \mathrm{Wu} \mathrm{Z}$, Mo X. Maternal folic acid supplementation and the risk of congenital heart defects in offspring: a meta-analysis of epidemiological observational studies. Sci Rep. 2015;5:8506.

24. Goh YI, Bollano E, Einarson TR, Koren G. Prenatal multivitamin supplementation and rates of congenital anomalies: a meta-analysis. J Obstet Gynaecol Can. 2006;28:680-9.

25. Siu SC, Sermer M, Colman JM, Alvarez AN, Mercier LA, Morton BC, Kells CM, Bergin ML, Kiess MC, Marcotte F, Taylor DA, Gordon EP, Spears JC, Tam JW, Amankwah KS, Smallhorn JF, Farine D, Sorensen $\mathrm{S}$. Cardiac disease in pregnancy I: prospective multicenter study of pregnancy outcomes in women with heart disease. Circulation. 2001;104:515-21. 
26. Drenthen W, Boersma E, Balci A, Moons P, Roos-Hesselink JW, Mulder BJM, Vliegen HW, van Dijk APJ, Voors AA, Yap SC, van Veldhuisen DJ, Pieper PG. Predictors of pregnancy complications in women with congenital heart disease. Eur Heart J. 2010;31:2124-32.

27. Thorne S, MacGregor A, Nelson-Piercy C. Risks of contraception and pregnancy in heart disease. Heart. 2006;92:1520-5.

28. Ruys TPE, Cornette J, Roos-Hesselink JW. Pregnancy and delivery in cardiac disease. J Cardiol. 2013;61:107-12.

29. Emmanuel Y, Thorne SA. Heart disease in pregnancy. Best Pract Res Clin Obstet Gynaecol. 2015;29:579-97.

30. Sunitha M, Chandrasekharappa S, Brid SV. Electrocradiographic Qrs Axis, Q wave and T-wave changes in 2nd and 3rd trimester of normal pregnancy. J Clin Diagn Res. 2014;8:17-21.

31. Ratnapalan S, Bentur Y, Koren G. Doctor, will that $\mathrm{X}$-ray harm my unborn child? CMAJ Can Med Assoc J. 2008;179:1293-6.

32. Cong J, Fan T, Yang X, Squires JW, Cheng G, Zhang L, Zhang Z. Structural and functional changes in maternal left ventricle during pregnancy: a three-dimensional speckle-tracking echocardiography study. Cardiovasc Ultrasound. 2015;13:6.

33. Bamfo JEAK, Kametas NA, Nicolaides KH, Chambers JB. Maternal left ventricular diastolic and systolic long-axis function during normal pregnancy. Eur J Echocardiogr. 2007;8:360-8.

34. Savu O, Jurcut R, Giusca S, van Mieghem T, Gussi I, Popescu BA, Ginghina C, Rademakers F, Deprest J, Voigt JU. Morphological and functional adaptation of the maternal heart during pregnancy. Circ Cardiovasc Imaging. 2012;5:289-97.

35. Estensen ME, Beitnes JO, Grindheim G, Aaberge L, Smiseth OA, Henriksen T, Aakhus S. Altered maternal left ventricular contractility and function during normal pregnancy. Ultrasound Obstet Gynecol. 2013;41:659-66.

36. Rokey R, Hsu HW, Moise KJ Jr, Adam K, Wasserstrum N. Inaccurate noninvasive mitral valve area calculation during pregnancy. Obstet Gynecol. 1994;84:950-5.

37. Gatzoulis MA, Webb GD, Daubeney PEF. Diagnosis and management of adult congenital heart disease. Philadelphia: Elsevier; 2010.

38. De Wilde JP, Rivers AW, Price DL. A review of the current use of magnetic resonance imaging in pregnancy and safety implications for the fetus. Prog Biophys Mol Biol. 2005;87:335-53.

39. Iball GR, Brettle DS. Use of lead shielding on pregnant patients undergoing CT scans: results of an international survey. Radiography. 2011;17:102-8.

40. Roos-Hesselink JW, Ruys TPE, Stein JI, Thilén U, Webb GD, Niwa K, Kaemmerer H, Baumgartner H, Budts W, Maggioni AP, Tavazzi L, Taha N, Johnson MR, Hall R. Outcome of pregnancy in patients with structural or ischaemic heart disease: results of a registry of the European Society of Cardiology. Eur Heart J. 2013;34:657-65.

41. Tanous D, Siu SC, Mason J, Greutmann M, Wald RM, Parker JD, Sermer M, Colman JM, Silversides CK. B-type natriuretic peptide in pregnant women with heart disease. J Am Coll Cardiol. 2010;56:1247-53.

42. Siu SC, Sermer M, Colman JM, Alvarez AN, Mercier L-A, Morton BC, Kells CM, Bergin ML, Kiess MC, Marcotte F, Taylor DA, Gordon EP, Spears JC, Tam JW, Amankwah KS, Smallhorn JF, Farine D, Sorensen S. Prospective multicenter study of pregnancy outcomes in women with heart disease. Circulation. 2001;104:515-21.

43. Sliwa K, Hilfiker-Kleiner D, Petrie MC, Mebazaa A, Pieske B, Buchmann E, Regitz-Zagrosek V, Schaufelberger M, Tavazzi L, van Veldhuisen DJ, Watkins H, Shah AJ, Seferovic PM, Elkayam U, Pankuweit S, Papp Z, Mouquet F, McMurray JJV. Current state of knowledge on aetiology, diagnosis, management, and therapy of peripartum cardiomyopathy: a position statement from the Heart Failure Association of the European Society of Cardiology Working Group on peripartum cardiomyopathy. Eur J Heart Fail. 2010;12:767-78.

44. Yamac H, Bultmann I, Sliwa K, Hilfiker-Kleiner D. Prolactin: a new therapeutic target in peripartum cardiomyopathy. Heart. 2010;96:1352-7.

45. Bello N, Hurtado Rendon IS, Arany Z. The relationship between preeclampsia and peripartum cardiomyopathy: a systematic review and meta-analysis. J Am Coll Cardiol. 2013;62:1715-23.

46. Hilfiker-Kleiner D, Meyer GP, Schieffer E, Goldmann B, Podewski E, Struman I, Fischer P, Drexler $\mathrm{H}$. Recovery from postpartum cardiomyopathy in 2 patients by blocking prolactin release with bromocriptine. J Am Coll Cardiol. 2007;50:2354-5.

47. Sliwa K, Blauwet L, Tibazarwa K, Libhaber E, Smedema J-P, Becker A, McMurray J, Yamac H, Labidi S, Struman I, Hilfiker-Kleiner D. Evaluation of bromocriptine in the treatment of acute severe peripartum cardiomyopathy. A proof-of-concept pilot study. Circulation. 2010;121:1465-73. 
48. McNamara DM, Elkayam U, Alharethi R, Damp J, Hsich E, Ewald G, Modi K, Alexis JD, Ramani GV, Semigran MJ, Haythe J, Markham DW, Marek J, Gorcsan Iii J, Wu W-C, Lin Y, Halder I, Pisarcik J, Cooper LT, Fett JD. Clinical outcomes for peripartum cardiomyopathy in North America: results of the IPAC study (investigations of pregnancy-associated cardiomyopathy). J Am Coll Cardiol. 2015;66:905-14.

49. Habli M, O'Brien T, Nowack E, Khoury S, Barton JR, Sibai B. Peripartum cardiomyopathy: prognostic factors for long-term maternal outcome. Am J Obstet Gynecol 2008; 199:415.e411-415.e415.

50. Elkayam U, Tummala PP, Rao K, Akhter MW, Karaalp IS, Wani OR, Hameed A, Gviazda I, Shotan A. Maternal and fetal outcomes of subsequent pregnancies in women with peripartum cardiomyopathy. N Engl J Med. 2001;344:1567-71.

51. Modi KA, Illum S, Jariatul K, Caldito G, Reddy PC. Poor outcome of indigent patients with peripartum cardiomyopathy in the United States. Am J Obstet Gynecol. 2009;201(171):e171-5.

52. Roos-Hesselink JW, Ruys TP, Stein JI, Thilen U, Webb GD, Niwa K, Kaemmerer H, Baumgartner H, Budts W, Maggioni AP, Tavazzi L, Taha N, Johnson MR, Hall R, ROPAC Investigators. Outcome of pregnancy in patients with structural or ischaemic heart disease: results of a registry of the European Society of Cardiology. Eur Heart J. 2013;34:657-65.

53. Silversides CK, Colman JM, Sermer M, Siu SC. Cardiac risk in pregnant women with rheumatic mitral stenosis. Am J Cardiol. 2003;91:1382-5.

54. Silversides CK, Colman JM, Sermer M, Farine D, Siu SC. Early and intermediate-term outcomes of pregnancy with congenital aortic stenosis. Am J Cardiol. 2003;91:1386-9.

55. Norrad RS, Salehian O. Management of severe mitral stenosis during pregnancy. Circulation. 2011;124:2756-60.

56. Hameed A, Karaalp IS, Tummala PP, Wani OR, Canetti M, Akhter MW, Goodwin I, Zapadinsky N, Elkayam U. The effect of valvular heart disease on maternal and fetal outcome of pregnancy. J Am Coll Cardiol. 2001;37:893-9.

57. Adamson DL, Nelson-Piercy C. Managing palpitations and arrhythmias during pregnancy. Heart. 2007;93:1630-6.

58. Tromp CHN, Nanne ACM, Pernet PJM, Tukkie R, Bolte AC. Electrical cardioversion during pregnancy: safe or not? Neth Heart J. 2011;19:134-6.
59. Bulava A, Hanis J, Eisenberger M. Catheter ablation of atrial fibrillation using zero-fluoroscopy technique: a randomized trial. Pacing Clin Electrophysiol. 2015;38:797-806.

60. Ertekin E, van Hagen IM, Salam AM, Ruys TPE, Johnson MR, Popelova J, Parsonage WA, Ashour Z, Shotan A, Oliver JM, Veldtman GR, Hall R, Roos-Hesselink JW. Ventricular tachyarrhythmia during pregnancy in women with heart disease: data from the ROPAC, a registry from the European Society of Cardiology. Int $\mathrm{J}$ Cardiol. 2016;220:131-6.

61. Natale A, Davidson T, Geiger MJ, Newby K. Implantable cardioverter-defibrillators and pregnancy. A safe combination? Circulation. 1997;96:2808-12.

62. Seth R, Moss AJ, McNitt S, Zareba W, Andrews ML, Qi M, Robinson JL, Goldenberg I, Ackerman MJ, Benhorin J, Kaufman ES, Locati EH, Napolitano C, Priori SG, Schwartz PJ, Towbin JA, Vincent GM, Zhang L. Long QT syndrome and pregnancy. J Am Coll Cardiol. 2007;49:1092-8.

63. Adekanye O, Srinivas K, Collis RE. Bradyarrhythmias in pregnancy: a case report and review of management. Int J Obstet Anesth. 2007;16:165-70.

64. Herman SC, Zhou J. Isoproterenol infusion for treatment of refractory symptomatic bradycardia in parturients with congenital complete heart block. Int J Obstet Anesth. 2011;20:361-3.

65. Roth A, Elkayam U. Acute myocardial infarction associated with pregnancy. J Am Coll Cardiol. 2008;52:171-80.

66. James AH, Jamison MG, Biswas MS, Brancazio LR, Swamy GK, Myers ER. Acute myocardial infarction in pregnancy. A United States population-based study. Circulation. 2006;113:1564-71.

67. Curtis SL, Marsden-Williams J, Sullivan C, Sellers SM, Trinder J, Scrutton M, Stuart AG. Current trends in the management of heart disease in pregnancy. Int J Cardiol. 2008;133:62-9.

68. Canobbio MM, Warnes CA, Aboulhosn J, Connolly HM, Khanna A, Koos BJ, Mital S, Rose C, Silversides C, Stout K, American Heart Association Council on Cardiovascular and Stroke Nursing; Council on Clinical Cardiology; Council on Cardiovascular Disease in the Young; Council on Functional Genomics and Translational Biology; and Council on Quality of Care and Outcomes Research. Management of pregnancy in patients with complex congenital heart disease: a scientific statement for healthcare professionals from the American Heart Association. Circulation. 2017;135:e50-87. 
69. Mulder BJ, Meijboom LJ. Pregnancy and marfan syndrome: an ongoing discussion. J Am Coll Cardiol. 2012;60:230-1.

70. McKellar SH, MacDonald RJ, Michelena HI, Connolly HM, Sundt TM. Frequency of cardiovascular events in women with a congenitally bicuspid aortic valve in a single community and effect of pregnancy on events. Am J Cardiol. 2011;107:96-9.

71. Sillesen M, Hjortdal V, Vejlstrup N, Sorensen K. Pregnancy with prosthetic heart valves-30 years nationwide experience in Denmark. Eur J Cardiothorac Surg. 2011;40:448-54.

72. van Hagen IM, Roos-Hesselink JW, Ruys TPE, Merz WM, Goland S, Gabriel H, Lelonek M, Trojnarska O, Al Mahmeed WA, Balint HO, Ashour Z, Baumgartner $\mathrm{H}$, Boersma $\mathrm{E}$, Johnson $\mathrm{MR}$, Hall $\mathrm{R}$, and on behalf of the ROPAC investigators and the EORP team. Pregnancy in women with a mechanical heart valve: data of the European Society of Cardiology Registry of Pregnancy and Cardiac Disease (ROPAC). Circulation 2015;132(2):132-42. doi: 10. 1161/CIRCULATIONAHA.115.015242

73. Vitale N, De Feo M, De Santo LS, Pollice A, Tedesco N, Cotrufo M. Dose-dependent fetal complications of warfarin in pregnant women with mechanical heart valves. J Am Coll Cardiol. 1999;33:1637-41.

74. Khamoushi AJ, Kashfi F, Hosseini S, Alizadeh Ghavidel AR, Samiei N, Haddadzadeh M. Anti-coagulation during pregnancy in women with mechanical heart valves: a prospective study. Int J Fertil Steril. 2011;5:47-51.

75. Cotrufo M, De Luca TSL, Calabro R, Mastrogiovanni G, Lama D. Coumarin anticoagulation during pregnancy in patients with mechanical valve prostheses. Eur J Cardiothorac Surg. 1991;5:300-5.
76. Soma-Pillay P, Nene Z, Mathivha TM, Macdonald AP. The effect of warfarin dosage on maternal and fetal outcomes in pregnant women with prosthetic heart valves. Obstet Med. 2011;4:24-7.

77. Alshawabkeh L, Economy KE, Valente AM. Anticoagulation during pregnancy: evolving strategies with a focus on mechanical valves. J Am Coll Cardiol. 2016;68:1804-13.

78. Patel JP, Green B, Patel RK, Marsh MS, Davies JG, Arya R. Population pharmacokinetics of enoxaparin during the antenatal period. Clinical perspective. Circulation. 2013;128:1462-9.

79. Ruys TPE, Roos-Hesselink JW, Pijuan-Domènech A, Vasario E, Gaisin IR, Iung B, Freeman LJ, Gordon EP, Pieper PG, Hall R, Boersma E, Johnson MR. Is a planned caesarean section in women with cardiac disease beneficial? Heart. 2015;101:530-6.

80. Esteves-Pereira AP, Deneux-Tharaux C, Nakamura-Pereira M, Saucedo M, Bouvier-Colle $\mathrm{M}-\mathrm{H}$, Leal MdC. Cesarean delivery and postpartum maternal mortality: a population-based case control study in Brazil. PLoS One. 2016;11:e0153396.

81. Ruys TPE, Roos-Hesselink JW, Pijuan-Domènech A, Vasario E, Gaisin IR, Iung B, Freeman LJ, Gordon EP, Pieper PG, Hall R, Boersma E, Johnson MR, Investigators obotR: Is a planned caesarean section in women with cardiac disease beneficial? Heart. 2015;101:530-6.

82. Cauldwell M, Steer PJ, Swan L, Uebing A, Gatzoulis MA, Johnson MR. The management of the third stage of labour in women with heart disease. Heart. 2017;103:945-51. 